\title{
Characterization of the Ergosterol Biosynthesis Pathway in Ceratocystidaceae
}

\author{
Mohammad Sayari ${ }^{1,2, *}$, Magrieta A. van der Nest ${ }^{1,3}$, Emma T. Steenkamp ${ }^{1}$, Saleh Rahimlou ${ }^{4}(\mathbb{D}$, \\ Almuth Hammerbacher ${ }^{1}(D)$ and Brenda D. Wingfield ${ }^{1}(\mathbb{D}$ \\ 1 Department of Biochemistry, Genetics and Microbiology, Forestry and Agricultural Biotechnology \\ Institute (FABI), University of Pretoria, Pretoria 0002, South Africa; vandernestm@arc.agric.za (M.A.v.d.N.); \\ emma.steenkamp@fabi.up.ac.za (E.T.S.); almuth.hammerbacher@fabi.up.ac.za (A.H.); \\ brenda.wingfield@fabi.up.ac.za (B.D.W.) \\ 2 Department of Plant Science, University of Manitoba, 222 Agriculture Building, \\ Winnipeg, MB R3T 2N2, Canada \\ 3 Biotechnology Platform, Agricultural Research Council (ARC), Onderstepoort Campus, \\ Pretoria 0110, South Africa \\ 4 Department of Mycology and Microbiology, University of Tartu, 14A Ravila, 50411 Tartu, Estonia; \\ Saleh.Rahimlou@ut.ee \\ * Correspondence: Mohammad.Sayari@umanitoba.ca; Fax: +1-204-474-7528
}

Citation: Sayari, M.; van der Nest, M.A.; Steenkamp, E.T.; Rahimlou, S.; Hammerbacher, A.; Wingfield, B.D. Characterization of the Ergosterol Biosynthesis Pathway in Ceratocystidaceae. J. Fungi 2021, 7, 237. https://doi.org/10.3390/ jof7030237

Academic Editor: Willem Melchers

Received: 24 February 2021

Accepted: 16 March 2021

Published: 22 March 2021

Publisher's Note: MDPI stays neutral with regard to jurisdictional claims in published maps and institutional affiliations.

Copyright: (c) 2021 by the authors. Licensee MDPI, Basel, Switzerland. This article is an open access article distributed under the terms and conditions of the Creative Commons Attribution (CC BY) license (https:// creativecommons.org/licenses/by/ $4.0 /)$.

\begin{abstract}
Terpenes represent the biggest group of natural compounds on earth. This large class of organic hydrocarbons is distributed among all cellular organisms, including fungi. The different classes of terpenes produced by fungi are mono, sesqui, di- and triterpenes, although triterpene ergosterol is the main sterol identified in cell membranes of these organisms. The availability of genomic data from members in the Ceratocystidaceae enabled the detection and characterization of the genes encoding the enzymes in the mevalonate and ergosterol biosynthetic pathways. Using a bioinformatics approach, fungal orthologs of sterol biosynthesis genes in nine different species of the Ceratocystidaceae were identified. Ergosterol and some of the intermediates in the pathway were also detected in seven species (Ceratocystis manginecans, C. adiposa, Huntiella moniliformis, Thielaviopsis punctulata, Bretziella fagacearum, Endoconidiophora polonica and Davidsoniella virescens), using gas chromatography-mass spectrometry analysis. The average ergosterol content differed among different genera of Ceratocystidaceae. We also identified all possible terpene related genes and possible biosynthetic clusters in the genomes used in this study. We found a highly conserved terpene biosynthesis gene cluster containing some genes encoding ergosterol biosynthesis enzymes in the analysed genomes. An additional possible terpene gene cluster was also identified in all of the Ceratocystidaceae. We also evaluated the sensitivity of the Ceratocystidaceae to a triazole fungicide that inhibits ergosterol synthesis. The results showed that different members of this family behave differently when exposed to different concentrations of triazole tebuconazole.
\end{abstract}

Keywords: ergosterol; Ceratocystidaceae; terpenes; biosynthetic gene cluster

\section{Introduction}

Fungi produce a large variety of terpenoids that form part of a structurally and functionally diverse class of natural compounds [1]. They are involved in an array of biological processes ranging from those needed for the adaptation to particular environmental niches to those needed for the interaction with other organisms [2]. Despite this variety, all terpenoids are made from simple five-carbon precursor molecules to form compounds containing two or more isoprene units [1]. The terpenoid compounds of fungi can have two, three, four or six isoprene units, respectively referred to as monoterpenes, sesquiterpenes, diterpenes and triterpenes [3]. Most known terpene synthases of fungi catalyze the formation of sesquiterpenes, and only a few diterpene and triterpene synthases are known, and no known bona fide monoterpene synthases [1]. 
Although steroids are a major group of natural triterpenoids [4], fungi lack a large diversity of these compounds [1]. In most cases, ergosterol (24-methylcholesta-5, 7, 22trien3b-ol) is their major sterol [5], with the main exception being primitive fungi such as those in the Chytridiomycota where cholesterol (cholest-5-en-3 $\beta$-ol) is the main sterol [6]. These sterols are primarily found in cell membranes where it has diverse functions including processes essential for growth and development, the regulation of cell wall permeability, and adaptation to stress [7].

The processes involved in ergosterol and cholesterol biosynthesis have been elucidated using studies on Saccharomyces cerevisiae, as well as various fungi [6-9]. In general, the first set of steps involves the synthesis of farnesyl pyrophosphate (FPP; a linear terpenoid with 15 carbons) from acetyl-coenzyme A (acetyl-CoA), after which the next set of catalytic steps produce squalene (a linear terpenoid with 30 carbons) from two molecules of FPP, with the final set of steps involving the conversion of squalene to lanosterol (a tetracyclic terpenoid with 30 carbons) and its modification at various positions to produce either ergosterol or cholesterol [10]. However, numerous variations are known among fungal species [11], especially in the later stages of the biosynthesis pathway [5]. Additionally, in some species, the pathway partially causes the production of other final products and no ergosterol [5]. Due to its role in biology, distinctive structural characteristics and the unique processes of its biosynthesis, ergosterol is regarded as an ideal target for fungicides [12]. For example, pathogenic fungi may be controlled using azole compounds that inhibit lanosterol 14- $\alpha$-demethylase, thereby blocking a key step in the conversion of lanosterol to ergosterol [13]. However, azole resistance in fungi has been reported, and the mechanisms allowing this include detoxification transporters, amino acid substitutions in lanosterol 14$\alpha$-demethylase protein binding sites and overexpression of the genes encoding lanosterol $14-\alpha$-demethylase [13]. Therefore, understanding ergosterol biosynthesis and potential resistance is important in the management of fungal pathogens.

Here we studied ergosterol and terpene biosynthesis in the very important plant pathogenic fungal family Ceratocystidaceae (Phylum Ascomycota, Order Microascales). Despite their economic importance, our knowledge regarding ergosterol biosynthesis or the production of other terpenoids in the Ceratocystidaceae is limited to only a few studies. Ergosterol was reported as the only sterol identified from Bretziella fagacearum (previously known as Ceratocystis fagacearum) using thin-layer chromatography and mass spectrometry [14]. In another study, the cyclic monoterpene alcohol isopulegol was isolated and identified from liquid cultures of Endoconidiophora coerulescens (previously known as Ceratocystis coerulescens) [15].

The overall goal of this study was to explore the potential of Ceratocystidaceae to produce ergosterol and other terpenoids. We accordingly identified genes involved in terpenoid biosynthesis using publicly available genome sequences for 23 species from the Ceratocystidaceae (Table 1). We then used gas chromatography-mass spectrometry (GC-MS) analysis to evaluate the production of intermediates of the ergosterol biosynthesis pathway in seven representatives of the family (i.e., C. manginecans, C. adiposa, Huntiella moniliformis, Thielaviopsis punctulata, Br. fagacearum, E. polonica and Davidsoniella virescens). Finally, we evaluated the sensitivity of Ceratocystidaceae to an azole fungicide. The findings of this study increase our knowledge of ergosterol biosynthesis in Ceratocystidaceae, which can be applied for developing new antifungal compounds targeting this pathway. The results of the study thus provide a valuable starting point for future studies, particularly regarding the control of pathogenic species Ceratocystidaceae.

\section{Materials and Methods}

\subsection{Fungal Genomes and Cultures}

We used the available genomic sequences from 23 species from eight genera in the Ceratocystidaceae (Table 1). These included Ceratocystis (C. manginecans, C. fimbriata, $C$. eucalypticola, C. harringtonii, C. smalleyii, C. albifundus, C. platani and C. adiposa), Huntiella (H. moniliformis, H. decipiens, H. bhutanensis, H. omanensis and H. savannae), Thielaviopsis 
(T. punctulata and T. musarum), Bretziella (Br. fagacearum), Endoconidiophora (E. polonica and E. laricicola), Ambrosiella (A.xylebori), Davidsoniella (D. virescens, D. neocaledoniae and D. australis) and Berkeleyomyces (Be. basicola). These genomes were previously shown to have high levels of completeness [16,17], suggesting that they would be useful for the identification of putative genes in involved in terpenoid biosynthesis.

For the sterol detection and quantification studies, seven representative species were used. These were C. manginecans, C. adiposa, H. moniliformis, T. punctulata, Br. fagacearum, E. polonica and $D$. virescens. The entire set of 23 fungi were also used for the in vitro fungicide sensitivity assay. The isolates were routinely cultured at $25{ }^{\circ} \mathrm{C}$ in the dark on malt extract agar (MEA) medium (2\% Bacto ${ }^{\mathrm{TM}}$ malt extract [BD BioSciences, San Jose, CA USA], 2\% Difco $^{\mathrm{TM}}$ agar [BD BioSciences]). All isolates are available from the culture collection of the Forestry and Agricultural Biotechnology Institute (FABI) fungal.

Table 1. Isolates numbers and genome sequence information for the species used in this study.

\begin{tabular}{|c|c|c|c|}
\hline Species & Isolate Number ${ }^{a}$ & GenBank Accession Number & References \\
\hline B. fagacearum & CMW2656 & MKGJ00000000 & [18] \\
\hline C. adiposa & CMW2573 & LXGU00000000 & [19] \\
\hline H. moniliformis & CMW10134 & JMSH00000000 & [20] \\
\hline T. punctulata & BPI 893173 & LAEV00000000 & {$[21]$} \\
\hline D. virescens & CMW17339 & LJZU000000000 & [22] \\
\hline D. neocaledoniae & CMW 225392 & RHDR00000000 & [16] \\
\hline D. australis & CMW 2333 & RHLR00000000 & [17] \\
\hline E. polonica & CMW20930 & LXKZ00000000 & [19] \\
\hline A. xylebori & CBS110.61 & PCDO00000000 & [23] \\
\hline Be. basicola & CMW49352 & PJAC00000000 & [24] \\
\hline C. manginecans & CMW17570 & JJRZ00000000 & {$[20]$} \\
\hline C. fimbriata & CMW 15049 & APWK00000000 & [25] \\
\hline C. eucalypticola & CMW 11536 & LJOA00000000 & [22] \\
\hline C. harringtonii & CMW 14789 & MKGM0000000 & [18] \\
\hline C. smalleyii & CMW 14800 & NETT01000000 & {$[24]$} \\
\hline C. albifundus & CMW 13980 & JSSU000000000 & [26] \\
\hline E. laricicola & CMW 20928 & LXGT00000000 & [19] \\
\hline H. decipiens & CMW 30855 & NETU00000000 & [27] \\
\hline H. bhutanensis & CMW 8217 & MJMS00000000 & [18] \\
\hline H. omanensis & CMW 11056 & JSUI000000000 & [26] \\
\hline H. savannae & CMW 17300 & LCZG00000000 & [28] \\
\hline T. musarum & CMW 1546 & LKBB00000000 & [22] \\
\hline C. platani & CF0 & LBBL00000000 & [29] \\
\hline
\end{tabular}

a Isolates with CMW numbers may be obtained from the culture collection of the Tree Protection Cooperative Programme (TPCP), Forestry and Agricultural Biotechnology Institute (FABI), University of Pretoria, Pretoria, South Africa. Those with CBS and BPI numbers may be obtained from Centraalbureau voor Schimmel cultures, CBS Fungal Biodiversity Centre and the US National Fungus Collections, Systematic Botany and Mycology Laboratory, Maryland, U.S.A.

\subsection{Identification of Terpene Biosynthesis Genes and Gene Clusters}

For identifying potential terpenoid biosynthesis genes and gene clusters, the respective genome sequences were submitted, to antiSMASH [30]. The Open reading frames (ORFs) identified were further examined using the InterPro web portal [31], after which signature sequences were inferred with MOTIF (http:/ / www.genome.jp/tools/motif/ accessed on 
5 January 2021). The contigs identified by antiSMASH to contain terpene biosynthesis genes and gene clusters were also examined manually. For this purpose, any ORF in approximately 15kilobase pair upstream and downstream of the predicted core gene (i.e., a terpene synthase coding gene) were screened against the nonredundant protein database of the National Centre for Biotechnology Information (NCBI; http:/ / www.ncbi.nlm.nih.gov accessed on 5 January 2021) using BLASTp and tBLASTn searches (Expect value $[E] \leq$ $10^{-6}$ ) to find their orthologs.

\subsection{Ergosterol Biosynthesis Pathway Prediction}

The GhostKoala tool of the Kyoto Encyclopedia of Genes and Genomes (KEGG) [32] was used to add metabolic annotations to all of the genes encoded by each genome. The ergosterol biosynthesis pathway in Ceratocystidaceae was then predicted using the KEGG Mapper-Search\&colour Pathway tool (http:/ / www.genome.jp/kegg/tool/map_ pathway2 accessed on 5 January 2021). These analyses were done using the whole genome sequences of all of the fungi included (Table 1), with the only exception being A. xylebori because of an assembly problem that caused incorrect prediction of the pathway. As a reference, we used the genome of Fusarium graminearum (GenBank accession number AACM00000000). The annotation of homologous genes from each species was checked using both AUGUSTUS [33] and Fgenesh [34].

The genome sequences included in this study were also interrogated for the presence of putative genes involved in the production of the intermediate mevalonate and of ergosterol using BLASTn analyses $\left(\mathrm{E} \leq 10^{-6}\right)$ in CLC Genomic Workbench version 11.0.1 (Qiagen Bioinformatics, Aarhus, Denmark). The gene sequences used in this analysis included those that are part of the mevalonate pathway, namely genes coding for ERG8 (EWZ41759) from Fusarium oxysporum, ERG10 (EDV11184 and EDN61111) from S. cerevisiae, ERG12 (EWZ48657) from F. oxysporum, ERG13 (PTB67186) from Trichoderma citrinoviride, ERG20 (ESU12927) from F. graminearum, isopentenyl-diphosphate delta-isomerase (ESU16336) from F. graminearum and diphosphomevalonate decarboxylase (ESU17136) from F. graminearum. Those that are part of the ergosterol biosynthesis phase of the pathway included genes coding for ERG1 (AAA34592) from S. cerevisiae, ERG2 (RKL43533), ERG5 (RKL44214) and ERG7 (RBA08815) from F. proliferatum, ERG3 (PCD36290), ERG4 (EFX01240) and ERG6 (ESU10532) from F. graminearum, ERG9 (ABX64425) and ERG25 (KLO95654) from F. fujikuroi, ERG11 (DAA06695), ERG24 (EDN62547) and ERG27 (EDN59646) from S. cerevisiae.

\subsection{Intron/Exon Architecture of the Ceratocystidaceae ERG Genes}

The intron and exon positions of putative ERG genes in the genomes included in this study were manually confirmed using CLC Genomic Workbench and Geneious version 11.1.5 (https: / / www.geneious.com/geneious/ accessed on 5 January 2021). The intronexon boundaries for the genes in H. moniliformis and C. fimbriata were also confirmed by mapping publicly available transcripts $[35,36]$ to the different genes of these two species. For this purpose, the available RNAseq reads were quality filtered in CLC Genomics Workbench version 9.1.1.0 using a read length over $300 \mathrm{bp}$ and a Phred quality score of below $20(\mathrm{Q} \leq 0.01)$. The resulting RNASeq data for each of the isolates were then mapped to the different genes identified, using the RNA-legacy tool in CLC Genomics Workbench with a minimum similarity fraction of 0.8 and minimum length fraction of 0.5 .

\subsection{Phylogenetic Analysis of the Putative ERG11 and ERG13 Genes of the Ceratocystidaceae}

Genes encoding hydroxymethylglutaryl-CoA synthase (ERG13) and lanosterol 14- $\alpha$ demethylase (ERG11) obtained from the 23 genomes used in this study, were subjected to phylogenetic analysis. These genes are highly conserved, present in all eukaryotic kingdoms, and are believed to have evolved prior to the divergence of most eukaryotic families [37]. Accordingly, the datasets analysed included the respective ERG11 and ERG13 sequences from all of the Ceratocystidaceae genomes analysed, together with previously sequenced genes acquired from the top blast hits in the NCBI database. For 
outgroup purposes, ERG11 sequences from Ustilago hordei (CCF50451), Sporisorium reilianum (CBQ68278), Malassezia vespertilionis (PKI85412) and Malassezia sympodialis (XP_018740314) were used. For ERG13, the sequences from Wallemia mellicola (XP_006959548) and Ustilago maydis (XP_011392062) served as outgroups.

For both the datasets, alignments based on amino acid residues were performed using MAFFT (Multiple Alignment using Fast Fourier Transform; [38]) with default parameters. From these datasets, phylogenetic trees were inferred using the MEGA7 package [39] and the best-fit substitution models indicated by ProtTest [40]. These were JTT+I+G for ERG11 and $\mathrm{LG}+\mathrm{I}+\mathrm{G}+\mathrm{F}$ in the case of ERG13) Branch support was estimated using the same model parameters and 1000 pseudo replicates.

\subsection{Sterol Detection and Quantification}

Lipid extraction from fungal cultures was done as described before [41]. Briefly, this involved inoculation of $200 \mathrm{~mL}$ of malt extract broth (MEB; $2 \%$ Bacto $^{\mathrm{TM}}$ malt extract [BD BioSciences, San Jose, CA, USA]) with a small block of agar overgrown with mycelium and incubation for 14 days at $25^{\circ} \mathrm{C}$ in the darkness with shaking at $150 \mathrm{rpm}$ (222DS Benchtop Shaking Incubator; Labnet international, Edison, NJ, USA). Fungal tissue was then collected by filtration through filter paper (Whatman, Maidstone, United Kingdom), washed with distilled water, and freeze-dried. Sterols were then extracted from $50 \mathrm{mg}$ lyophilized mycelium by saponification at $80{ }^{\circ} \mathrm{C}$ for $90 \mathrm{~min}$ in a $500 \mu \mathrm{L}$ solution containing $10 \%(w / v) \mathrm{KOH}$ in methanol. To this mixture, $250 \mu \mathrm{L}$ distilled water was added and left to cool to $25^{\circ} \mathrm{C}$. The solution was then subjected to three rounds organic extraction using $1 \mathrm{~mL}$ hexane. The pooled hexane fractions were evaporated to dryness under a stream of nitrogen and dissolved in $100 \mu \mathrm{L}$ methanol.

The samples were derivatized using $50 \mu \mathrm{L}$ N-methyl-N-trimethylsilyl-trifluoroacetamide (Macherey-Nagel, Dueren, Germany) for $2 \mathrm{~h}$ at $40^{\circ} \mathrm{C}$ before analysis using a gas chromatograph attached to a quadrupole mass spectrometer with an electron impact ion source (Agilent 59736890 GC MS, Agilent, Santa Clara, USA). A standard 30 m HP-5ms capillary column (Agilent) was used with a constant flow of helium of $1 \mathrm{~mL} \mathrm{~min}^{-1}$. Sample $(1 \mu \mathrm{L})$ was injected with a 1:10 split ratio. The injector temperature was kept at $230{ }^{\circ} \mathrm{C}$. The oven temperature was ramped from an initial $70{ }^{\circ} \mathrm{C}$ to $320^{\circ} \mathrm{C}$ at a constant rate of $6{ }^{\circ} \mathrm{C} \mathrm{min}{ }^{-1}$, with a final hold time of $3 \mathrm{~min}$. The mass spectrometer was operated in full scan mode with a mass range of 50-350 $\mathrm{m} \mathrm{z}^{-1}$. The ion source was kept at $70 \mathrm{eV}$ at $250{ }^{\circ} \mathrm{C}$.

Compounds were identified by spectral comparisons with the NIST library version 12 (National Institute for Standards and Technology, Boulder, USA), retention indices and when available, retention times of pure standards. Peaks were integrated and quantified relative to a calibration curve produced for cholesterol. All experiments were done in three independent replications. Data were imported into the open-source R-based statistics program Metaboanalyst (https: / / www.metaboanalyst.ca/faces/home.xhtml accessed on 5 January 2021), normalized using the natural logarithm. Hierarchical clustering was performed with the hclust function in the $\mathrm{R}$ package using Euclidean distance as the similarity measure and the Ward's linkage clustering algorithm.

\subsection{In Vitro Azole Sensitivity}

The sensitivity of the fungi to tebuconazole (1-(4-Chlorophenyl)-4,4-dimethyl-3-(1H1,2,4-triazol-1-ylmethyl)-3-pentanol, $250 \mathrm{~g} / \mathrm{L}$, Bayer, Leverkusen, Germany) was examined using the mycelial inhibition technique. Sensitivity to the compound was evaluated by transferring a 4-mm mycelial block was obtained from the growing edge of a 1-week-old MEA culture to the center of a Petri plate containing MEA medium supplemented the fungicide. For this purpose, tebuconazole concentrations of 75, 50, 25, 12.5, 6.25, 3 and $1.5 \mu \mathrm{g} \mathrm{L}^{-1}$ were used. The inoculated plates were then incubated for 7 days at $25{ }^{\circ} \mathrm{C}$ in the dark after which fungal colony diameters were measured. Four replicates were considered per concentration. 
All measurements were subjected to one-way analysis of variance (ANOVA). An individual analysis was performed for each dependent variable and each fungal species on the repeated dataset. Assumption of normality and homogeneity of variance were assessed prior to the analysis. Means were compared using Tukey's test at a statistical significance of $p \leq 0.05$. The analysis was conducted by the statistics program $\mathrm{R}$ using "agricolae" package [42].

\section{Results}

\subsection{Identification of Terpene Biosynthesis Genes and Gene Clusters}

AntiSMASH detected two different terpenoid biosynthesis gene clusters in all the genomes examined in this study (Figure 1). The first cluster was part of the ergosterol biosynthesis pathway, because it contained genes encoding a steroid-binding protein, DnaJ, Squalene synthase, delta 24-sterol reductase, a protease and a mannoyl transferase coding genes (Figure 1A; Supplementary File S1). The second cluster included a core gene encoding geranylgeranyl pyrophosphate synthetase [43], which was flanked by genes encoding a cell division protein, MFS transporter, peroxisomal membrane protein, arsenite transmembrane transporter and a hypothetical protein (Figure 1B; Supplementary File S1). In H. moniliformis this second cluster was on the same contig, but $50 \mathrm{~kb}$ away, from a gene encoding lanosterol synthase (a key gene in ergosterol biosynthesis pathway [44]). In all other members of the Ceratocystidaceae, the lanosterol synthase encoding gene was located on a separate contig.

Even though antiSMASH analysis did not identify other genes in the ergosterol biosynthesis pathway, investigation of the genomes using KEGG and BLASTp analysis identified additional genes involved in the pathway. These included genes coding for phosphomevalonate kinase (ERG8), C-14 demethylase (ERG11) and C8 sterol isomerase (ERG2) from H. moniliformis, H. omanensis, H. bhutanensis and H. savannae (Supplementary File S3). In $H$. decipiens, genes coding for ERG2 and ERG8 were found on the same contig (NETU00000079) and gene coding for ERG11 on another contig (NETU00000037). However, in all other members of Ceratocystidaceae different $E R G$ genes were scattered throughout the genome and found in different contigs.

Investigation of the genomes using BLAST analysis followed by a manual curation confirmed the presence of two putative terpene synthase coding gene sequences. However, BLAST searches across all Ceratocystidaceae fungal genomes produced five positive hits for putative terpene synthase coding genes in some genomes that were not used for further analysis, due to being either too big (E. polonica, E. laricicola) or too small (H. moniliformis) to resemble a typical terpene synthase. pBLAST analysis of these genes also confirmed that they likely did not represent terpene synthase coding genes.

\subsection{Ergosterol Biosynthesis Pathway Prediction}

We were able to find the gene repertoire for ergosterol biosynthesis in different members of Ceratocystidaceae using KEGG and BLASTp analysis. Based on these analyses, all the genes that form the ergosterol biosynthesis pathway were present in the genomes included in this study (Figure 2; File S3). These included genes encoding the recognized enzymes involved in ergosterol biosynthesis in S. cerevisiae [45], beginning with Acetyl Co-A and its ultimate conversion to ergosterol [8]. In the following section, we present the gene homologues in different Ceratocystidaceae following their order in the predicted ergosterol biosynthesis pathway.

The gene homologues from the first phase of the pathway (synthesis of FPP from Acetyl $\mathrm{Co}-\mathrm{A})$ that were identified in the Ceratocystidaceae included those encoding for acetyl-CoA C-acetyltransferase, ERG13 (hydroxymethylglutaryl-CoA synthase), hydroxymethylglutarylCoA reductase (HMGCR), ERG12 (mevalonate kinase), ERG8 (phosphomevalonate kinase) and ERG20 (farnesyl diphosphate synthase) (Supplementary File S3). 
A

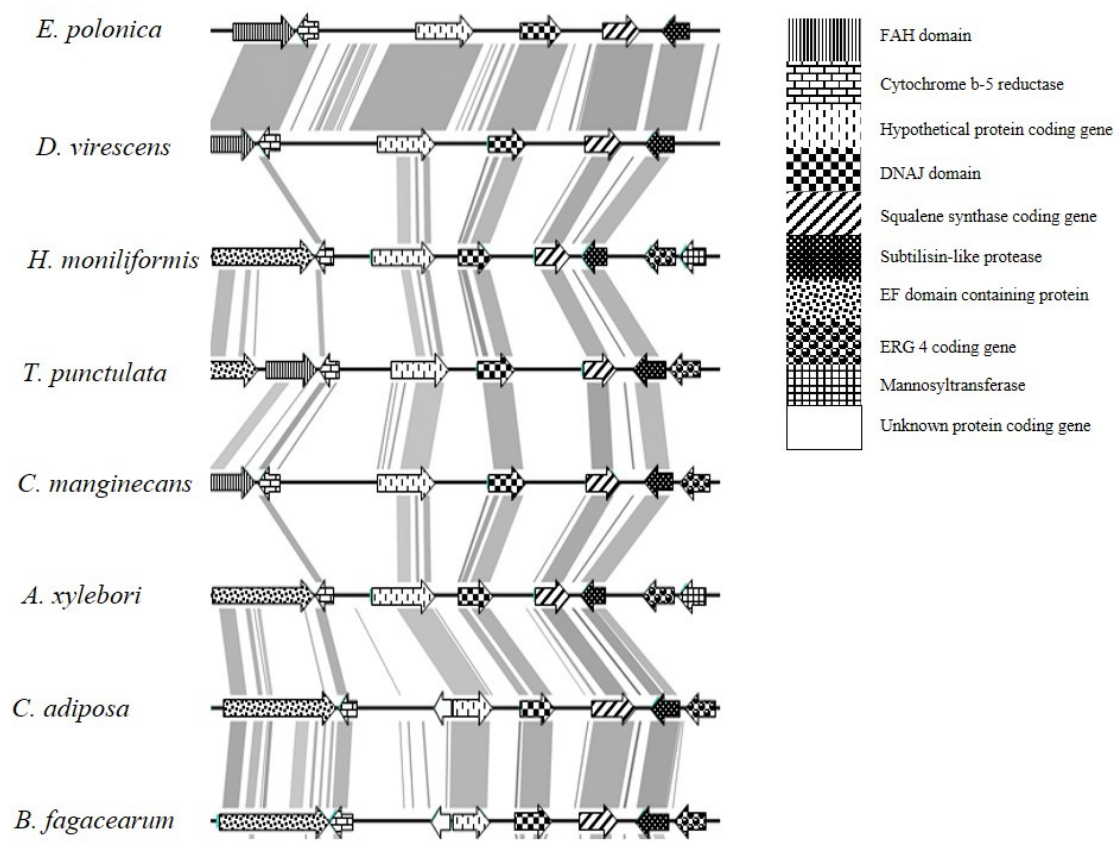

B
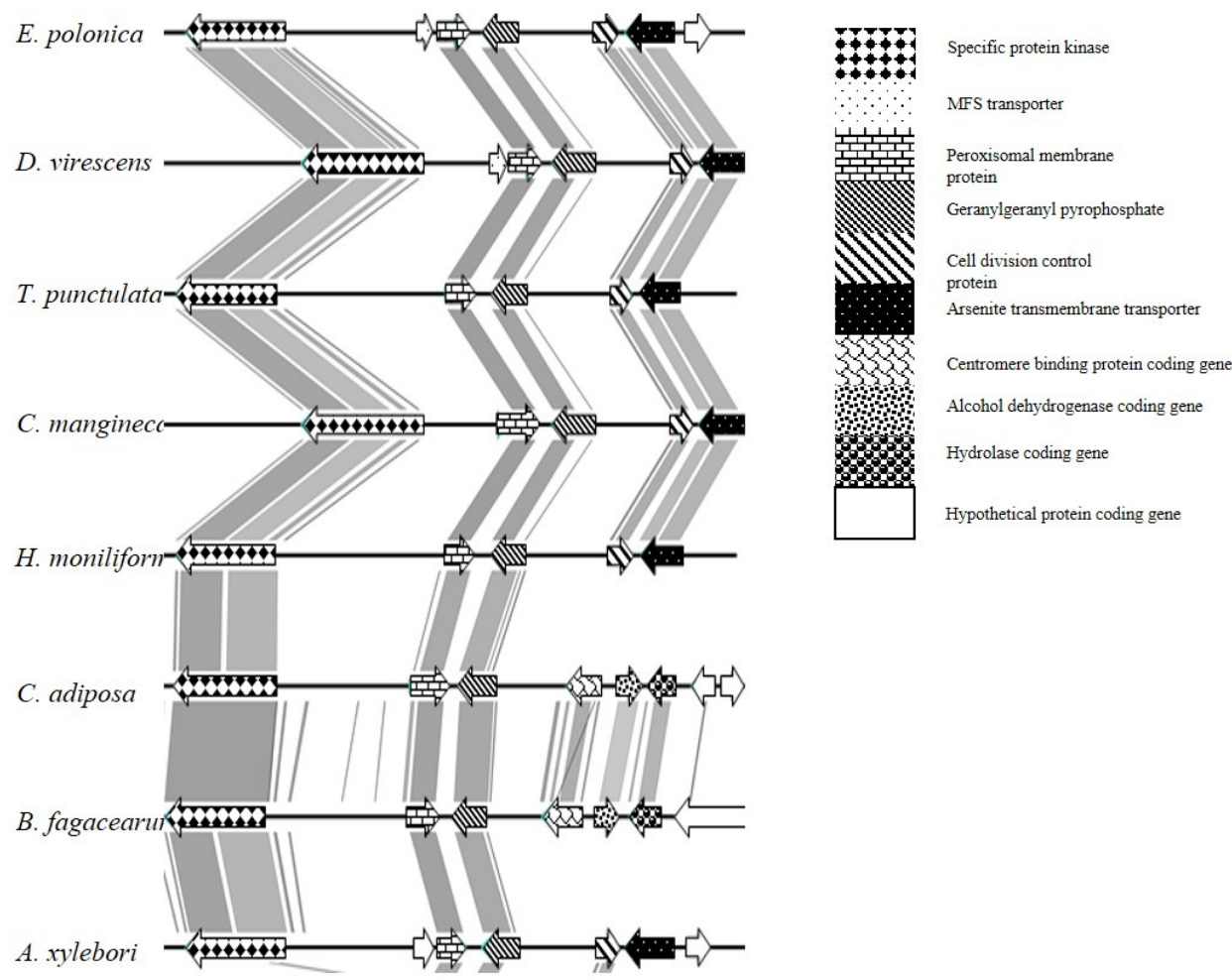

Figure 1. Comparison of gene content and organization of the two terpenoid biosynthesis clusters identified in different members of Ceratocystidaceae. One of these clusters (A) contained genes needed for ergosterol biosynthesis. The other contained a gene encoding geranylgeranyl pyrophosphate synthetase (B) which may be involved in protein prenylation or potentially in the production of carotenoids or antimicrobial diterpenes (Keller et al., 2005). The direction and relative size of genes are indicated by arrows. The function of putative synthetic genes is shown by different patterns. Each color/pattern represents a specific gene. 
With regards to the second phase of ergosterol biosynthesis (synthesis of ergosterol from FPP), we found the gene coding for the conserved squalene synthase (ERG9) among all the Ceratocystidaceae examined. BLASTp analysis of squalene synthase from different Ceratocystidaceae showed a very high similarity to those of different Ascomycetes such as Neurospora tetrasperma (an average of 88-92\%, XP_009853279) and Sordaria macrospora (an average of 87-89\% XP_003345124). Overall, the Ceratocystidaceae squalene synthase protein sequences shared $87-64 \%$ amino acid similarity with those of other Ascomycota. A similar trend of high similarity (88-61\%) among the Ceratocystidaceae was also observed for the next enzyme in the pathway, squalene monooxygenase (ERG1). This enzyme is responsible for the formation of oxidosqualene by epoxidation of squalene [46]. Its protein sequences in the Ceratocystidaceae were most similar to those of Verticillium longiospermum (an average of 64\%, CRK44748), Verticillium dahliae (an average of 65\%, PNH40870) and Hypoxylon sp. (an average of 66\%, OTA91656).

Proteins encoded by ERG7, ERG11 and ERG24 respectively responsible for formation of lanosterol from squalene epoxide and the subsequent demethylation and reduction of lanosterol, to ultimately form 14-Dimethyl-lanosterol were also found in all the genomes examined. The Ceratocystidaceae ERG7 protein sequences shared high similarity to its homologs in Colletotrichum graminicola (an average of 74\%, XP_008098265), Lemontospora prolificans (an average of 72\%, PKS07236) and Scedosporium apiospermum (an average of $70 \%$, XP_016640229). The ERG11 protein sequences from the Ceratocystidaceae also shared high similarity to homologs in other fungi (an average of $76 \%$ to Lemontospora prolificans, AWO72586, 71\% to Scedosporium apiospermum, AWO72588, 73\% to Metarhizium robertsii, XP_007820238), while those of ERG24 shared high similarity to homologs from fungi such as Scedosporium apiospermum (an average of 66\%, XP_016642425) and Lemontospora prolificans (an average of 69\%, PKS10286).

Genes coding for ERG25 (encoding C-4 sterol methyl oxidase), ERG26 (encoding sterol 4- $\alpha$-carboxylate 3-dehydrogenase) and ERG27 (encoding 3-keto sterol reductase) work together as enzymatic complexes [47] and were present in all the Ceratocystidaceae genomes examined. ERG25 sequences of Lemontospora prolificans (an average of 78\%, PKS08950) and Scedosporium apiospermum (an average of 76\%, XP_016640914) were most similar to those of the Ceratocystidaceae. The ERG26 protein product is a member of the 3b-hydroxysteroid dehydrogenase family and removes the 3a-hydrogen from 4-Methyl zymosterol carboxylate, which results in the 3keto-4methyl zymosterol intermediate decarboxylation [48]. The identified ERG26 gene shared high similarity to those encoded by other Ascomycetes, e.g., an average of $75 \%$ to Lemontospora prolificans (AWO72586), an average of $77 \%$ to Scedosporium apiospermum (AWO72588) and an average of $74 \%$ to Metarhizium robertsii (XP_007820238). The ERG27 gene product catalyses formation of zymosterol from 3,keto4,methyl zymosterol [49]. The Ceratocystidaceae ERG27 protein sequences were most similar to those of Colletotrichum simmondsiis (an average of 79\%, KXH40884), Colletotrichum nymphaeae (an average of 76\%, KXH38700) and Colletotrichum salicis (an average of 77\%, KXH38261).

ERG6, catalyses the C-24 methylation of zymosterol to form fecosterol [50]. The putative protein sequence of ERG6 was most similar to species in the genus Colletotrichum (e.g., an average of $86 \%$ to Colletotrichum gloeosporioides (ELA25057), Colletotrichum chlorophyti (OLN94084) and Colletotrichum incanum (KZL83690). All the Ceratocystidaceae genomes encoded a ERG28 gene, which also showed high similarity to the homolog in Colletotrichum (e.g., Colletotrichum chlorophyti (an average of 98\%, OLN97423), Colletotrichum orchidophilum (an average of 95\%, XP_022474034).

Homologs of the genes coding for ERG2, ERG3, ERG4 and ERG5 were also detected in all the Ceratocystidaceae genomes examined. The products of these genes form the final part of the ergosterol biosynthetic pathway. The gene coding for ERG2 encodes sterol 8 -isomerase that moves the double bond of the $B$ ring of fecosterol from position 8 to position 7 to form Episterol [51]. The Ceratocystidaceae ERG2 protein sequences were most similar to those of Trichoderma asperellum (an average of 68\%, XP_024761716), Trichoderma 
atroviride (an average of 68\%, XP_013948848) and Chaetomium globosum (an average of 66\%, XP_001224797). ERG3 encodes sterol C-5 desaturase that catalyses formation of the double bond (carbon-carbon bond) in episterol, resulting in the formation of the toxic 2,7,24,28Ergosta trienol. The Ceratocystidaceae ERG3 were similar to those of other fungi, including Trichoderma reesei (an average of 67\%, XP_006965542), Trichoderma citrinoviride (an average of $66 \%$, XP_024749895) and Metarhizium bruneum (an average of 69\%, XP_014544386). Finally, ERG5 and ERG4, respectively encoding a P-450 Sterol C-22 desaturase and a C-24 sterol reductase, are responsible for the last two steps involving formation of the C-22 carboncarbon double bond in the sterol side chain to ergosta tetraenol and ultimate conversion of this molecule to ergosterol. The Ceratocystidaceae ERG5 was most similar to their corresponding homologs in fungi such as Purpureocillium lilacinum (an average of $77 \%$, PWI70663), Sordaria macrospora (an average of 75\%, XP_003348687) and Colletotrichum chlorophyti (an average of 78\%, OLN95588). In the case of ERG4, Ceratocystidaceae share 65-74\% identity with different Verticillium sequences ( $V$. alfalfa XP_003008950, V. dahliae XP_009649917 and V. longisporum CRK47680).
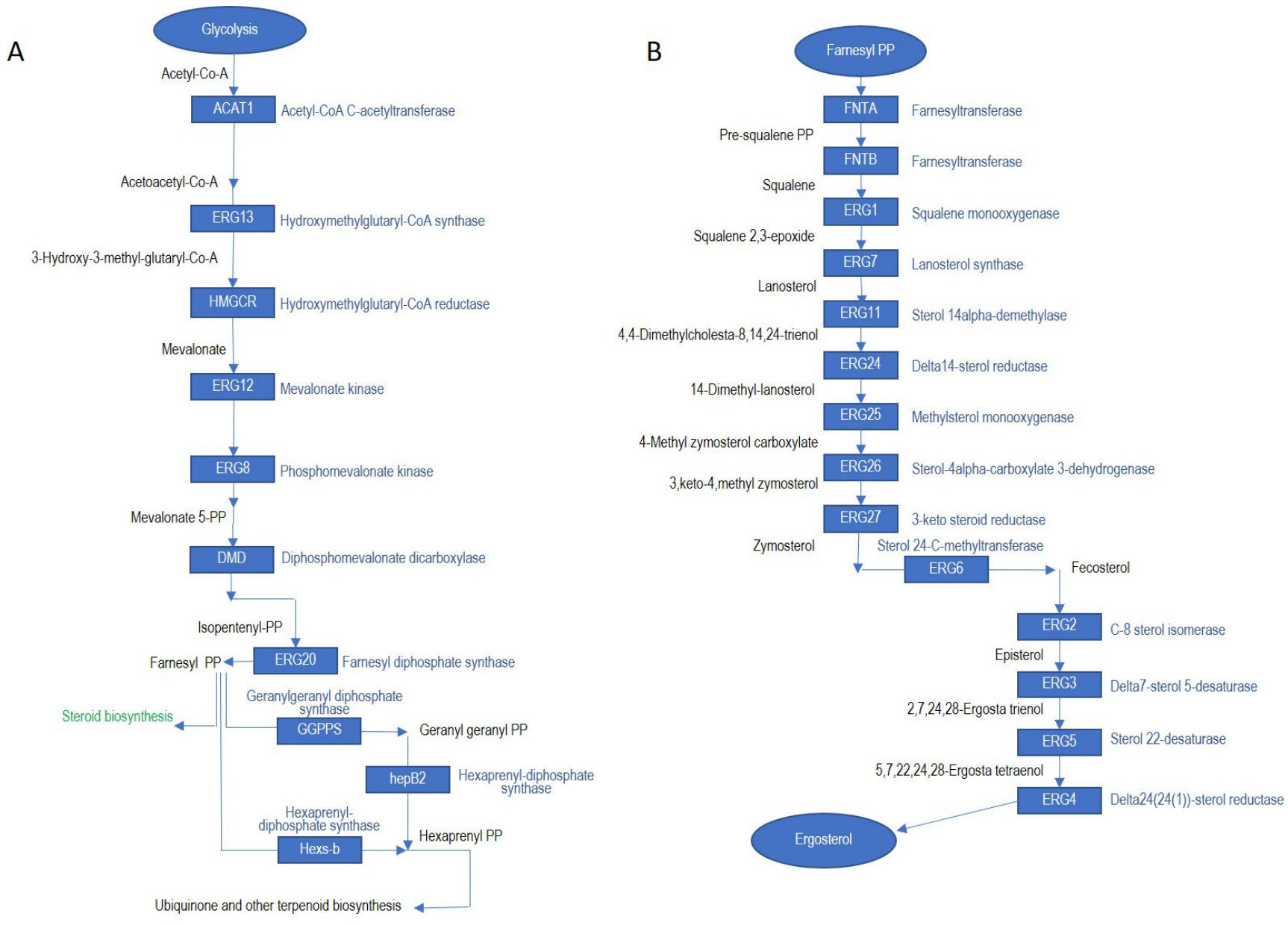

Figure 2. Possible ergosterol biosynthesis pathway in Ceratocystidaceae, as adapated from Bhattacharya et al. (2018). (A): the first part of the pathway from Acetyl-CoA to farnesyl pyrophosphate (FPP). (B): the last part of the pathway from FPP to ergosterol. ACAT1: Acetyl-CoA C-acetyltransferase, ERG13: Hydroxymethylglutaryl-CoA synthase, HMGCR: Hydroxymethylglutaryl-CoA reductase, ERG12: ERG12, ERG8: Phosphomevalonate kinase, DMD: Diphosphomevalonate dicarboxylase, ERG20: Farnesyl diphosphate synthase, GGPPS: Geranyl geranyl PP, hepB2: Hexaprenyl-diphosphate synthase, Hexs-b: Hexaprenyl PP, FNTA: Farnesyltransferase, FNTB: Farnesyltransferase, ERG1: Squalene monooxygenase, ERG7: Lanosterol synthase, ERG11: Sterol 14alpha-demethylase, ERG24: Delta14-sterol reductase, ERG25: Methylsterol monooxygenase, ERG26: Sterol-4alpha-carboxylate 3-dehydrogenase, ERG27: 3-keto steroid reductase, ERG6: Sterol 24-C-methyltransferase, ERG2: C-8 sterol isomerase, ERG3: Delta7-sterol 5-desaturase, ERG5: Sterol 22-desaturase, ERG4: Delta24(24(1))-sterol reductase. 


\subsection{Intron/Exon Architecture of the Ceratocystidaceae ERG Genes}

In all nine of the Ceratocystidaceae genomes in which intron-exon architecture was examined, the genes encoding ERG11, ERG8, ERG12, mevalonate diphosphate decarboxylase and ERG20, displayed similar intron-exon architectures. The only exception was ERG10, where A. xylebori and H. moniliformis had three introns while all the other Ceratocystidaceae had two. Mapping the RNAseq data to the ERG10 coding gene model in these fungi confirmed the intron and exon positions and distribution patterns observed for H. moniliformis and C. fimbriata.

The intron-exon architecture in the remainder of the ERG genes in the ergosterol pathway of different members of Ceratocystidaceae showed more diversity. For example, similar patterns were observed in Ceratocystidaceae genes coding for ERG1, ERG2 and $E R G 6$, but different intron-exon architectures were found within different Ceratocystidaceae for the genes coding for ERG4, ERG5, ERG7, ERG9, ERG13, ERG24 and ERG27 (Supplementary File S2).

\subsection{Phylogenetic Analysis the Putative ERG11 and ERG13 Genes of the Ceratocystidacea}

In this research we did the phylogeny analysis on two important genes of ergosterol biosynthesis pathways include ERG11 and ERG13 to shed light on their variability between different members of Ceratocystidaceae family and also to check if they follow the basic phylogenetical pattern of this family or if we can find any evidence of horizontal gene transfer among tested isolates. However, based on our analysis, Ceratocystidaceae sequences were separated into a well-supported clade in both the ERG11 and ERG13 trees (Figures 3 and 4). Moreover, in both cases, similar groupings amongst the Ceratocystidaceae sequences were seen. These groupings are congruent with the general taxonomy of Ceratocystidaceae [52].

\subsection{Sterol Identification and Quantification}

The sterol composition of the mycelium of the eight isolates representing eight genera from the family Ceratocystidaceae grown in MEA was evaluated using GC-MS (Supplementary File S4). Ergosterol was detected in the mycelium of all isolates where the concentrations ranged from 1.01 to $3.272 \mathrm{mg} \mathrm{g}^{-1}$ dry weight (wt) mycelia. Total ergosterol was $3.272 \mathrm{mg} \mathrm{g}^{-1}$ for C. adiposa, $1.679 \mathrm{mg} \mathrm{g}^{-1}$ for Br. fagacearum, $1.194 \mathrm{mg} \mathrm{g}^{-1}$ for T. punctulata, $3.127 \mathrm{mg} \mathrm{g}^{-1}$ for $\mathrm{H}$. moniliformis, $1.01 \mathrm{mg} \mathrm{g}^{-1}$ for $C$. manginecans, $3.005 \mathrm{mg} \mathrm{g}^{-1}$ for E. polonica and $1.492 \mathrm{mg} \mathrm{g}^{-1}$ for D. virescens.

The GC-MS examination of the total sterol fraction gained from different strains of Ceratocystidaceae showed that the main sterols present were lanosterol and ergosterol. However, we also detected ergosta-7,22-dien-3-ol, eburicol, 4-methyl ergosterol, fecosterol, and ergosta-5,8-dien-3-ol. The sterol profiles between the different genera included in this study differed widely (Figure 5). For instance, E. polonica and H. monilliformis showed similarities in their sterol profile with high levels of ergosterol and ergosta-5,8-dien-3-ol. On the other hand, the Ceratocystis species, T. punctulata and D. virescens shared high levels of 4-methyl ergosterol and lanosterol. 


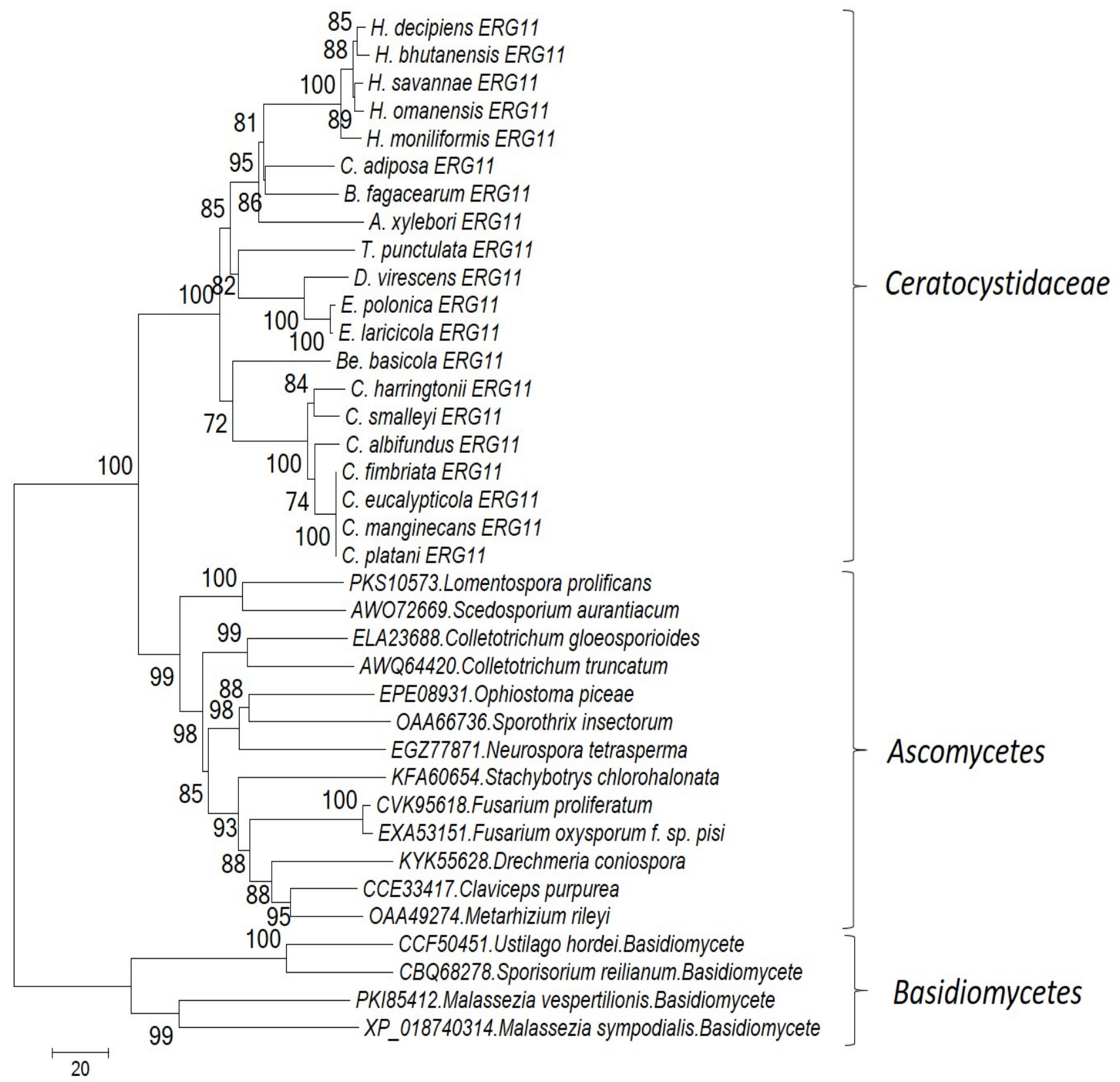

Figure 3. A maximum-likelihood tree of ERG11 protein sequences from different members of Ceratocystidaceae (one or more species of the following genera: Ceratocystis, Huntiella, Thielaviopsis, Bretziella, Endoconidiophora, Ambrosiella, Dadidsoniella and Berkeleyomyces), was achieved using the MEGA7 software and substitution model LG+I+G+F. The ERG11 from Ceratocystidaceae is shown with an underline. The evolutionary distances are in the units of the number of amino acid differences per sequence. The analysis involved 31 amino acid sequences. All positions with less than $95 \%$ site coverage were eliminated. 


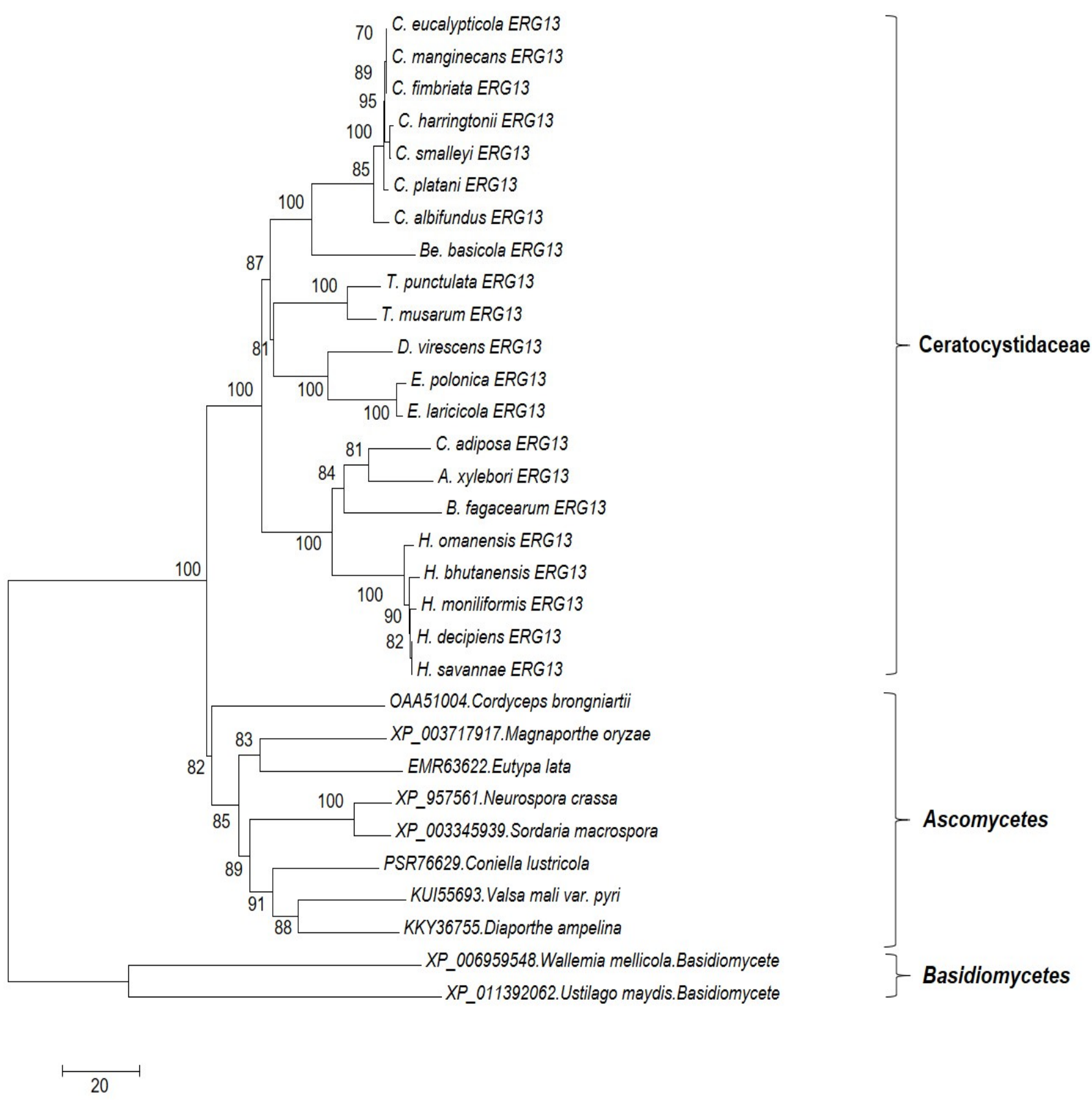

Figure 4. Phylogenetic tree performed on ERG13 protein sequences. This tree was constructed inferred using the maximum likelihood method using MEGA7 software. The optimal tree is shown. The percentage of replicate trees in which the associated taxa clustered together in the bootstrap test (1000 replicates) is shown next to the branches. The analysis involved 46 amino acid sequences. All positions with less than $95 \%$ site coverage were eliminated. That is, fewer than $5 \%$ alignment gaps, missing data, and ambiguous bases were allowed at any position. There was a total of 442 positions in the final dataset. Tree includes ERG13 proteins from one or more species of the following genera in the family Ceratocystidaceae: Ceratocystis, Huntiella, Thielaviopsis, Bretziella, Endoconidiophora, Ambrosiella, Dadidsoniella and Berkeleyomyces. 


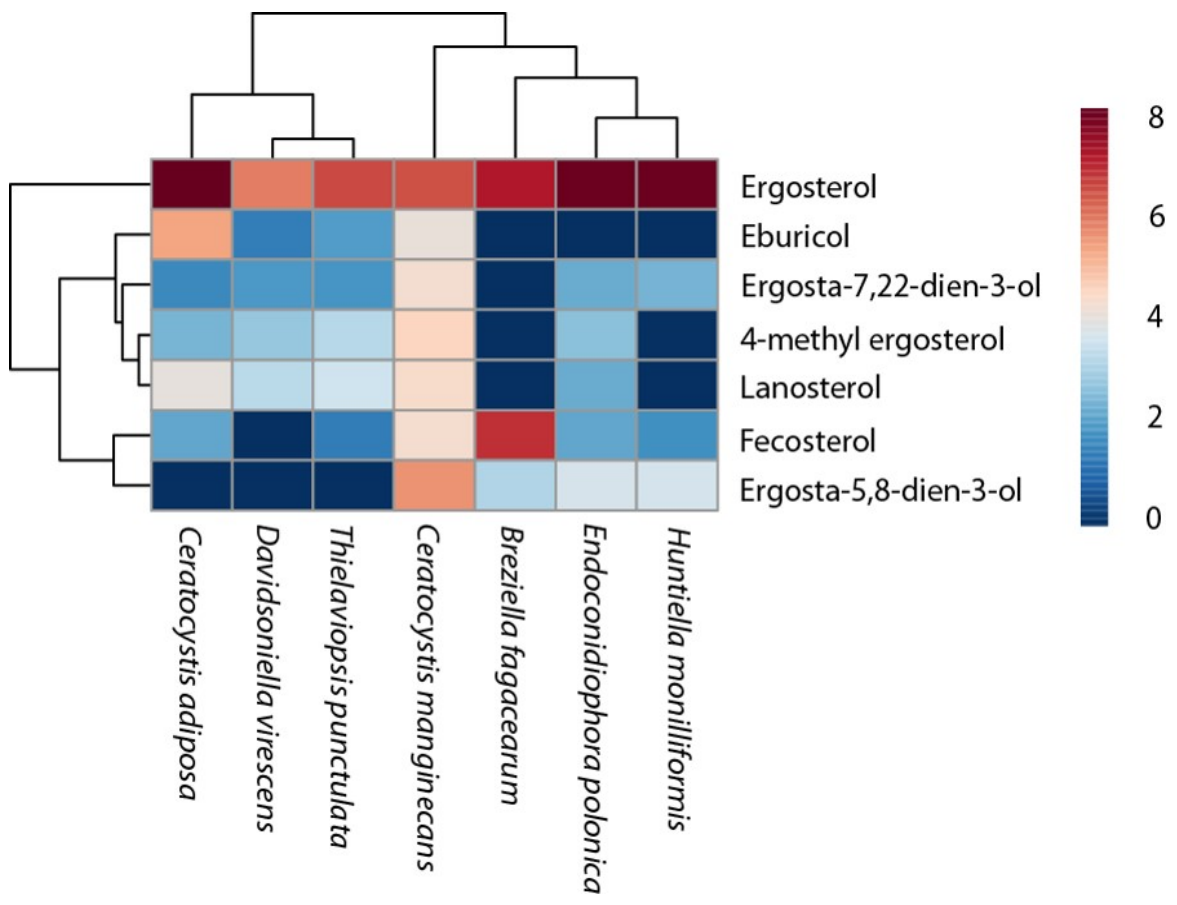

Figure 5. Heatmap of the sterol composition and ergosterol content in mycelia of isolates of the Ceratocystidaceae species: C. manginecans, H. moniliformis, T. punctulata, B. fagacearum, E. polonica and D. virescens grown in the MEB media for seven days. All three replicates are shown. Red and blue colours indicate higher and lower concentrations of the compounds, respectively.

\subsection{In Vitro Triazole Sensitivity of Ceratocystidaceae Isolates}

The different members of Ceratocystidaceae showed varying patterns of sensitivity to tebuconazole. Among all tested strains, C. adiposa, Thielaviopsis species and Davidsoniella species were least sensitive, whereas Br. fagacearum and Endoconidiophora species showed significantly higher sensitivity to triazole (Figure 6). This fungicide inhibited mycelial growth of Br. fagacearum, Davidsoniella and Huntiella species significantly more than Ceratocystis, Thielaviopsis and Endoconidiophora species at concentrations of 3 and $6 \mu \mathrm{g} \mathrm{L}^{-1}$ (Figure 6). At higher concentrations of 12.5 and $25 \mu \mathrm{g} \mathrm{L}^{-1}$ of Tebuconazole, inhibition was not significantly different among different strains except for Br. fagacearum which stopped growing at $25 \mu \mathrm{g} \mathrm{L}{ }^{-1}$. However, at these concentrations, C. adiposa and Thielaviopsis species were still more resistant compared to the other species. Endoconidiophora species growth was completely inhibited at $50 \mu \mathrm{g} \mathrm{L}^{-1}$. The growth of A. xylebori, Huntiella species as well as Ceratocystis species (except for $C$. manginecans) has stopped at $75 \mu \mathrm{g} \mathrm{L}^{-1}$. The other tested Ceratocystidaceae could still grow even at $75 \mu \mathrm{g} \mathrm{L}{ }^{-1}$. The list of all isolates used in the sensitivity study is shown in Supplementary File S5. 


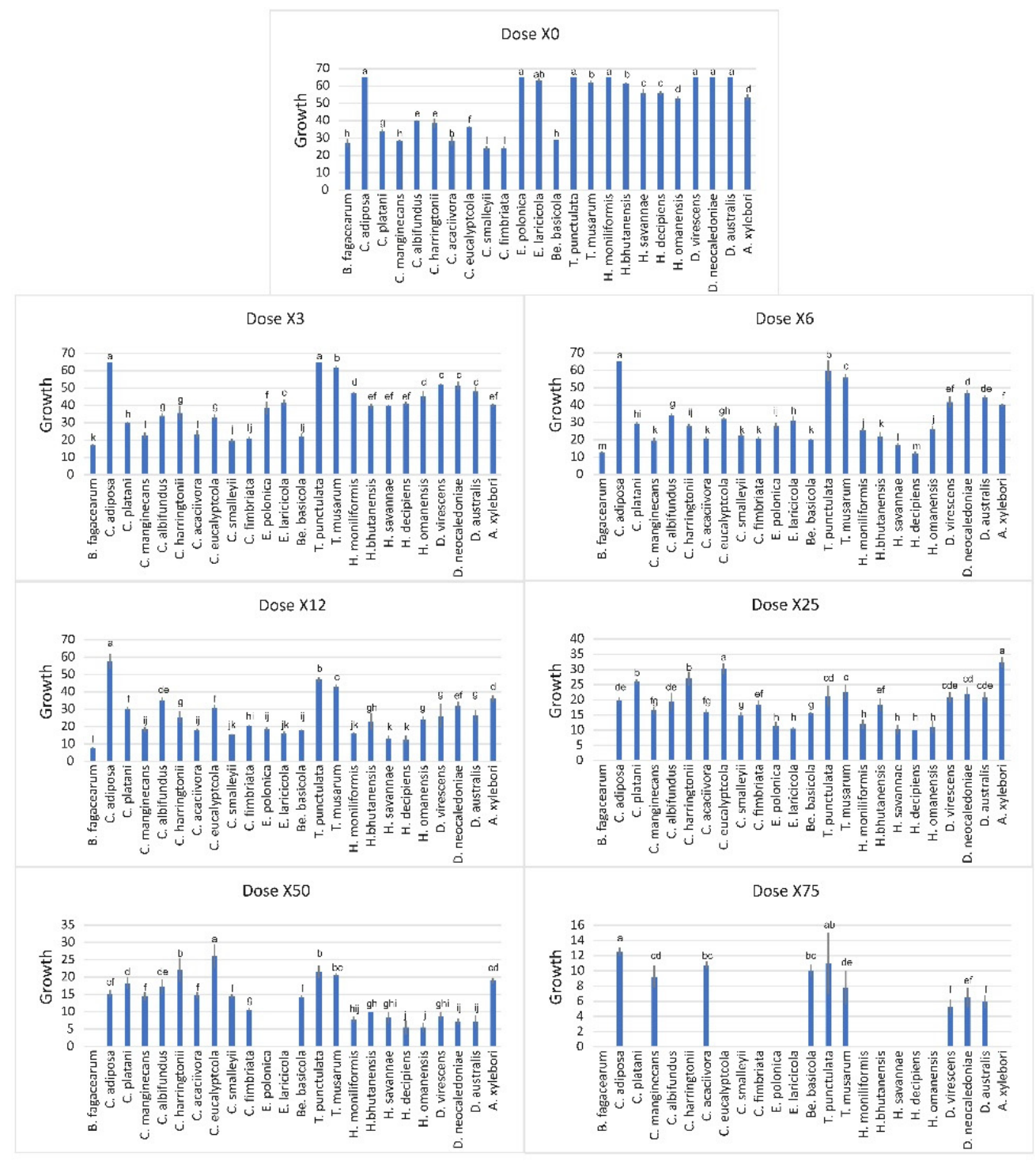

Figure 6. Effect of different triazole concentrations on mycelial growth of different Ceratocystidaceae including Ceratocystis (C. manginecans, C. fimbriata, C. eucalypticola, C. harringtonii, C. smalleyii, C. albifundus, C. platani and C. adiposa), Huntiella (H. moniliformis, H. decipiens, H. bhutanensis, $H$. omanensis and H. savannae), Thielaviopsis (T. punctulata and T. musarum), Bretziella (Br. fagacearum), Endoconidiophora (E. polonica and E. laricicola), Ambrosiella (A. xylebori), Davidsoniella (D. virescens, D. neocaledoniae and D. australis) and Berkeleyomyces (Be. basicola). Agar discs containing each isolate were grown for 7 days at $25{ }^{\circ} \mathrm{C}$ on MEA media amended with triazole at six different concentrations. Bars represent standard error. There were significant differences between means $(p<0.05)$ based on Tukey's test.

\section{Discussion}

Although ergosterol and steroid biosynthesis pathways have been extensively examined in model fungi, little is known about these pathways in non-model fungi, including those in the economically important Ceratocystidaceae. However, the availability of genome sequences, allowed us to fill this knowledge gap. The current study presents the first report of sterols, and ergosterol, in particular, produced by Ceratocystidaceae, as well as the putative biosynthetic pathway underlying ergosterol biosynthesis in these fungi. Basic knowledge of the Ceratocystidaceae ergosterol pathway is important as it could be used to develop inhibitors with a larger range or better activity. Results of this study can aid in the management of this important group of fungi, for example, the products identified in this study can have importance in the biocontrol process. 
Our results suggested that the Ceratocystidaceae representatives examined have a complete set of the enzymes known to be involved in the mevalonate and ergosterol biosynthesis pathways [8]. Since these putative genes are present in the Ceratocystidaceae genomes, as well as the genomes of other Ascomycota and in the Basidiomycota, these genes are postulated to have originated in an early common of these phyla [53]. Our finding is thus in-line with the hypothesis that genes involved in the ergosterol biosynthesis pathway are crucial for the survival of most fungal lineages of the Dikarya [7].

The Ceratocystidaceae encodes all of the gene products needed to convert Acetyl-CoA into ergosterol. Ergosterol biosynthesis is facilitated by 25 coding genes [8], where the first phase is characterized by the mevalonate pathway forming FPP, an important precursor for the biosynthesis of sterols in general, as well as dolichol, heme and prenylated proteins [10]. During this first phase, hydroxymethylglutaryl-CoA reductase (HMGCR) may catalyze the rate-limiting step, as is shown in other fungi [54]. During the second phase of ergosterol biosynthesis, ERG11 (lanosterol 14- $\alpha$-demethylase) and ERG1 (squalene epoxidase) likely catalyze rate-limiting steps [54], while ERG11 might also exert a regulatory effect on the ergosterol biosynthesis in general [55]. It would be interesting to see whether all of the genes identified in Ceratocystidaceae indeed fulfill their predicted roles, and to explore the intricacies that may or may not characterize ergosterol biosynthesis in these fungi.

Comparative analysis of this pathway in 23 members of Ceratocystidaceae showed that there are no duplicated genes in ergosterol biosynthetic pathway. This is congruent with what is observed in many yeasts, such as Candida albicans and S. cerevisiae [7]. However, this is different from many other Sordariomycetes in some species harbour more than one copy of certain ergosterol pathway genes. For instance, two genes coding for ERG3 were found in the genomes of F. circinatum and F. graminearum while, Magnaporthe grisea and F. graminearum, had three and two genes coding for ERG11, respectively [8,56]. Copy number variation is a significant source for genetic polymorphism and can lead to phenotypic diversity in the population [57]. Knowing the copy number can also help us with the functional characterization studies such as a gene knockout as genes with only one copy are the best targets for such experiments.

Like other fungi, terpenoid synthesis in the Ceratocystidaceae is carried out by genes that are clustered and co-regulated similar to that observed in other fungal biosynthetic pathways [58]. Such clustering is thought to allow for easier regulation through epigenetics and control by transcription factors, which are, in turn, crucial for the adaptation and survival of fungi under changing environmental conditions. Of the two terpenoid biosynthesisrelated clusters found in all the fungal genomes included in this study, both contained the expected genes (e.g., terpene synthases or cyclase genes as core gene, along with tailoring enzymes such as cytochrome P450 monoxygenases, oxidoreductases, transferases and $\mathrm{NAD}(\mathrm{P})+)[3]$. Where one of the clusters is likely involved ergosterol biosynthesis [46], the biological role of the other is unclear. It may be involved in the production of carotenoids or antimicrobial diterpenes, because the core gene of the first terpene cluster encodes a geranylgeranyl pyrophosphate synthetase (GGPS) that is documented to form carotenoids or antimicrobial diterpenes [59]. However, it is possible that this gene may be involved in the synthesis of geranylgeranyl for protein prenylation rather than for the synthesis of a secondary metabolite. This is because many fungi have two copies of the geranylgeranyl diphosphate synthase gene $[60,61]$. One of the geranylgeranyl diphosphate synthase genes in fungi is involved in protein prenylation, while the other gene product is involved in SM biosynthesis [62]. It is interesting that in Huntiella species, the GGPP-containing cluster was located in the vicinity of gene encoding lanosterol synthase. It might be possible that these gene clusters have an ancient origin which has been kept specifically in the genome of Huntiella. It is equally possible that the clustering in Huntiella is a more recent event.

The positional variation of introns in the ERG gene among different members of Ceratocystidaceae may suggest evolutionary events such as recombination or exon shuffling [63]. Positional dissimilarity (intron shuffling) was observed in the case of genes coding for ERG4, ERG5, ERG7, ERG9, ERG10, ERG13, ERG24 and ERG27. In contrast, the intron 
positions in ERG1, ERG2, ERG6, ERG8, ERG11 and ERG12 were conserved in all species. Intron shuffling in ERG11 among other fungi include Aspergillus niger, Nectria haematococca, Fusarium sporotrichioides, Penicillium italicum and Fusarium oxosporium [63]. The average intron size in the genes coding for ERG11 in Ceratocystidaceae was $69 \mathrm{bp}$, which is similar to the size predicted for other genes analysed from other fungi using genome sequencing [64]. The branching pattern for both the ERG11 and ERG13 phylogenies produced the same overall branching patterns and the intron conservation is congruent with these phylogenies. This might be likely to put some limitations on the history of sterol biosynthesis due to these explanations.

From this study, it is clear that Ceratocystidaceae members produce ergosterol as their main sterol. Our biochemical analysis revealed that $C$. manginecans had the lowest concentration of ergosterol and C. adiposa had the highest compared to the other members of the family. Ergosterol content of these fungi was comparable to levels found in other fungi such as Aspergillus amstelodami, Alternaria alternata and Aspergillus flavus (1 to $5 \mathrm{mg} \mathrm{mg}^{-1}$ dry weight) [65]. Although, the amount of ergosterol in Ceratocystidaceae was much higher than those measured from several other fungi associated with Xyleborus ambrosia beetles $(0.12 \%-0.24 \mu \mathrm{g} / \mathrm{mg})$ [66], it was still much lower than that quantified for fungi such as Aspergillus fumigatus, Candida albicans and Aspergillus flavus (up to $14 \mu \mathrm{g} / \mathrm{mg}$ ) [67].

In our analysis, we were unable to detect lanosterol in isolates of Br. fagacearum and $H$. moniliformis. We also could not identify any fecosterol in D. virescens. Diversity in sterol content and composition among Ceratocystidaceae is probably a result of differences amongst isolates and species, as well as differences in growth stage tested, growth temperature, and sterol isolation method [68]. Media composition was also reported to have an effect on sterol detection in fungi, but since all Ceratocystidaceae mycelia were grown in the same media, it is unlikely to be a variable for this study.

In Ceratocystidaceae, we could not detect any of the standard ergosterol pathway intermediates through zymosterol [6]. Rather, we found all intermediate sterols of fecosterol formation through eburicol. Fecosterol and eburicol were detected in some of the strains. These findings suggest that the production of fecosterol through eburicol in members of Ceratocystidaceae is the same as the pathway described for ergosterol biosynthesis in Aspergillus species [46].

Different members of Ceratocystidaceae showed different patterns of sensitivity to the triazole fungicide tebuconazole, indicating significant differences in ergosterol content or level of expression of the genes in the ergosterol pathway among these strains. This could be also a result of differences in the number of $A B C$ transporters which will result in different accumulation of the fungicide in fungal cells. Nevertheless, the results presented here are congruent with the outcomes of other reports in which the survival and growth and of C. fimbriata on Potato Dextrose Agar medium were completely halted by the triazole propiconazole [69]. In another study by Scruggs et al. (2017 [70]) on the in vitro effect of different chemicals on C. fimbriata, the ergosterol inhibitor fungicide, difenoconazole, was reported to be the most effective fungicide tested. The differences in azole sensitivity among different members of Ceratocystidaceae, as seen in the present study, demonstrates the necessity for further transcriptional and population-genetics studies in these microorganisms.

Supplementary Materials: The supplementary files are available: online at https:/ /www.mdpi.com/ 2309-608X/7/3/237/s1, Supplementary File S1. The sizes and positions of genes in the respective terpene clusters within the relevant contigs, together with the blast scores for the top database hits (i.e., E value, \% Coverage, \% identity and the Accession number of the top hit). Supplementary File S2. Tables represent number, position, and size of introns of the ERG genes in different Ceratocystidaceae. Supplementary File S3. The tables (AI) show the top tblastn hits NCBI's non-redundant nucleotide database for each of the Ceratocystidaceae genes involved in mevalonate (MVA) as well as ergosterol biosynthesis pathways. The blast scores (E-value, percent sequence identity and coverage) and the accession number of the top hits are indicated. Supplementary File S4. Isolates numbers and genome sequence information for the species used for the sterol detection and quantification studies. Supplementary File S5. Isolates used for the sensitivity test in this study. 
Author Contributions: Data analysis, M.S., A.H. and S.R.; validation of results, M.S. and A.H.; interpretation of the findings, M.S., M.A.v.d.N., E.T.S. and B.D.W.; methodology, M.S, A.H. and S.R.; formal analysis, M.S. and S.R.; writing-original draft preparation, M.S., M.A.v.d.N., S.R., A.H., E.T.S., B.D.W.; writing-review and editing, M.S, M.A.v.d.N., E.T.S. and B.D.W.; visualization, M.S, M.A.v.d.N., E.T.S. and B.D.W.; supervision, M.A.v.d.N., E.T.S. and B.D.W.; funding acquisition, E.T.S. and B.D.W. project administration, B.D.W. All authors have read and agreed to the published version of the manuscript.

Funding: Funding for this research was received from University of Pretoria, the South African National Research Foundation (NRF) and the South African Department of Science and Technology (DST) via the Centers of Excellence program (Center of Excellence in Tree Heath Biotechnology) and the South African Research Chairs Initiative (SARChI; SARChI Chair in Fungal Genomics).

Institutional Review Board Statement: Not applicable.

Informed Consent Statement: Not applicable.

Data Availability Statement: All data sets generated for this study are included in the manuscript and the supplementary files.

Acknowledgments: The authors are grateful to the anonymous reviewers for their insightful comments and suggestions.

Conflicts of Interest: The authors declare no conflict of interest.

\section{References}

1. Schmidt-Dannert, C. Biosynthesis of terpenoid natural products in fungi. In Inhibitors of Cell Growth; Metzler, J.B., Ed.; Springer: Cham, Switzerland, 2014; Volume 148, pp. 19-61.

2. Schmidt, R.; de Jager, V.; Zühlke, D.; Wolff, C.; Bernhardt, J.; Cankar, K.; Beekwilder, J.; van Ijcken, W.; Sleutels, F.; De Boer, W.; et al. Fungal volatile compounds induce production of the secondary metabolite Sodorifen in Serratia plymuthica PRI-2C. Sci. Rep. 2017, 7, 1-14. [CrossRef] [PubMed]

3. Quin, M.B.; Flynn, C.M.; Schmidt-Dannert, C. Traversing the fungal terpenome. Nat. Prod. Rep. 2014, 31, 1449-1473. [CrossRef] [PubMed]

4. Hill, R.A.; Connolly, J.D. Triterpenoids. Nat. Prod. Rep. 2013, 30, 1028-1065. [CrossRef]

5. Weete, J.D.; Abril, M.; Blackwell, M. Phylogenetic distribution of fungal sterols. PLoS ONE 2010, 5, e10899. [CrossRef]

6. Joffrion, T.M.; Cushion, M.T.; Grant, T. Sterol biosynthesis and sterol uptake in the fungal pathogen Pneumocystis carinii. FEMS Microbiol. Lett. 2010, 311, 1-9. [CrossRef]

7. Hu, Z.; He, B.; Ma, L.; Sun, Y.; Niu, Y.; Zeng, B. Recent advances in ergosterol biosynthesis and regulation mechanisms in Saccharomyces cerevisiae. Indian J. Microbiol. 2017, 57, 270-277. [CrossRef] [PubMed]

8. Da Silva Ferreira, M.E.; Colombo, A.L.; Paulsen, I.; Ren, Q.; Wortman, J.; Huang, J.; Goldman, M.H.S.; Goldman, G.H. The ergosterol biosynthesis pathway, transporter genes, and azole resistance in Aspergillus fumigatus. Med. Mycol. 2005, 43, S313-S319. [CrossRef] [PubMed]

9. Ceita, G.D.O.; Vilas-Boas, L.A.; Castilho, M.S.; Carazzolle, M.F.; Pirovani, C.P.; Selbach-Schnadelbach, A.; Gramacho, K.P.; Ramos, P.I.P.; Barbosa, L.V.; Pereira, G.A.G.; et al. Analysis of the ergosterol biosynthesis pathway cloning, molecular characterization

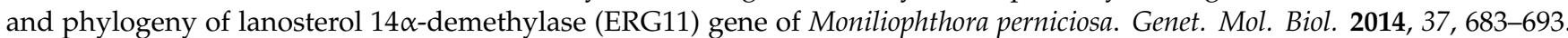
[CrossRef]

10. Lamb, D.C.; Kelly, D.E.; Manning, N.J.; Hollomon, D.W.; Kelly, S.L. Expression, purification, reconstitution and inhibition of Ustilago maydis sterol 14 $\alpha$-demethylase (CYP51; P45014DM). FEMS Microbiol. Lett. 1998, 169, 369-373. [CrossRef]

11. Kato, T. Sterol biosynthesis in fungi, a target for broad spectrum fungicides. In Chemistry of Plant Protection; Haug, G., Hoffman, H., Bowers, W.S., Ebing, W., Fukuto, T.R., Martin, D., Wegler, R., Yamamoto, I., Eds.; Springer: Berlin/Heidelberg, Germany; New York, NY, USA; Tokyo, Japan, 1996; pp. 1-24.

12. Dhingra, S.; Cramer, R.A. Regulation of sterol biosynthesis in the human fungal pathogen Aspergillus fumigatus: Opportunities for therapeutic development. Front. Microbiol. 2017, 8, 92. [CrossRef]

13. Price, C.L.; Parker, J.E.; Warrilow, A.G.; Kelly, D.E.; Kelly, S.L. Azole fungicides-Understanding resistance mechanisms in agricultural fungal pathogens. Pest Manag. Sci. 2015, 71, 1054-1058. [CrossRef] [PubMed]

14. Collins, R.P.; Kalnins, K. The occurrence of ergosterol in the Fungus Ceratocystis fagacearum. Mycologia 1969, 61, 645-646. [CrossRef] [PubMed]

15. Koch, W.-G.; Sinnwell, V. Isopulegol from liquid cultures of the Fungus Ceratocystis coerulescens (Ascomycotina). Z. Nat. C 1987, 42, 159-161. [CrossRef]

16. Sayari, M.; Van Der Nest, M.A.; Steenkamp, E.T.; Soal, N.C.; Wilken, P.M.; Wingfield, B.D. Distribution and evolution of nonribosomal peptide synthetase gene clusters in the Ceratocystidaceae. Genes 2019, 10, 328. [CrossRef] 
17. Sayari, M.; Steenkamp, E.T.; Van Der Nest, M.A.; Wingfield, B.D. Diversity and evolution of polyketide biosynthesis gene clusters in the Ceratocystidaceae. Fungal Biol. 2018, 122, 856-866. [CrossRef] [PubMed]

18. Wingfield, B.D.; Duong, T.A.; Hammerbacher, A.; van der Nest, M.A.; Wilson, A.; Chang, R.; Wilhelm de Beer, Z.; Steenkamp, E.T.; Markus Wilken, P.; Naidoo, K.; et al. IMA Genome-F 7 Draft genome sequences for Ceratocystis fagacearum, C. harringtonii, Grosmannia penicillata, and Huntiella bhutanensis. IMA Fungus 2016, 7, 317-323. [CrossRef]

19. Wingfield, B.D.; Ambler, J.M.; Coetzee, M.; De Beer, Z.W.; Duong, T.A.; Joubert, F.; Hammerbacher, A.; McTaggart, A.R.; Naidoo, K.; Nguyen, H.D.; et al. Draft genome sequences of Armillaria fuscipes, Ceratocystiopsis minuta, Ceratocystis adiposa, Endoconidiophora laricicola, E. polonica and Penicillium freii DAOMC 242723. IMA Fungus 2016, 7, 217-227. [CrossRef] [PubMed]

20. van der Nest, M.A.; Bihon, W.; De Vos, L.; Naidoo, K.; Roodt, D.; Rubagotti, E.; Slippers, B.; Steenkamp, E.T.; Wilken, P.M.; Wilson, A.; et al. Draft genome sequences of Diplodia sapinea, Ceratocystis manginecans, and Ceratocystis moniliformis. IMA Fungus 2014, 5, 135-140. [CrossRef]

21. Wingfield, B.D.; Ades, P.K.; Al-Naemi, F.A.; Beirn, L.A.; Bihon, W.; Crouch, J.A.; De Beer, Z.W.; De Vos, L.; Duong, T.A.; Fields, C.J.; et al. IMA Genome-F 4: Draft genome sequences of Chrysoporthe austroafricana, Diplodia scrobiculata, Fusarium nygamai, Leptographium lundbergii, Limonomyces culmigenus, Stagonosporopsis tanaceti, and Thielaviopsis punctulata. IMA Fungus 2015, 6, 233-248. [CrossRef] [PubMed]

22. Wingfield, B.D.; Barnes, I.; de Beer, Z.W.; De Vos, L.; Duong, T.A.; Kanzi, A.M.; Naidoo, K.; Nguyen, H.D.; Santana, Q.C.; Sayari, M.; et al. IMA Genome-F 5: Draft genome sequences of Ceratocystis eucalypticola, Chrysoporthe cubensis, C. deuterocubensis, Davidsoniella virescens, Fusarium temperatum, Graphilbum fragrans, Penicillium nordicum, and Thielaviopsis musarum. IMA Fungus 2015, 6, 493-506. [CrossRef]

23. Vanderpool, D.; Bracewell, R.R.; McCutcheon, J.P. Know your farmer: Ancient origins and multiple independent domestications of ambrosia beetle fungal cultivars. Mol. Ecol. 2018, 27, 2077-2094. [CrossRef] [PubMed]

24. Wingfield, B.D.; Bills, G.F.; Dong, Y.; Huang, W.; Nel, W.J.; Swalarsk-Parry, B.S.; Vaghefi, N.; Wilken, P.M.; An, Z.; de Beer, Z.W.; et al. IMA Genome-F 9: Draft genome sequence of Annulohypoxylon stygium, Aspergillus mulundensis, Berkeleyomyces basicola (syn. Thielaviopsis basicola), Ceratocystis smalleyi, two Cercospora beticola strains, Coleophoma cylindrospora, Fusarium fracticaudum, Phialophora cf. hyalina, and Morchella septimelata. IMA Fungus 2018, 9, 199-223.

25. Wilken, P.M.; Steenkamp, E.T.; Wingfield, M.J.; de Beer, Z.W.; Wingfield, B.D. Draft nuclear genome sequence for the plant pathogen, Ceratocystis fimbriata. IMA Fungus 2013, 4, 357-358. [CrossRef] [PubMed]

26. van der Nest, M.A.; Beirn, L.A.; Crouch, J.A.; Demers, J.E.; De Beer, Z.W.; De Vos, L.; Gordon, T.R.; Moncalvo, J.M.; Naidoo, K.; Sanchez-Ramirez, S.; et al. IMA Genome-F 3: Draft genomes of Amanita jacksonii, Ceratocystis albifundus, Fusarium circinatum, Huntiella omanensis, Leptographium procerum, Rutstroemia sydowiana, and Sclerotinia echinophila. IMA Fungus 2014, 5, 472-485. [CrossRef]

27. Wingfield, B.D.; Berger, D.K.; Steenkamp, E.T.; Lim, H.J.; Duong, T.A.; Bluhm, B.H.; De Beer, Z.W.; De Vos, L.; Fourie, G.; Naidoo, K.; et al. Draft genome of Cercospora zeina, Fusarium pininemorale, Hawksworthiomyces lignivorus, Huntiella decipiens and Ophiostoma ips. IMA Fungus 2017, 8, 385-396. [CrossRef]

28. Van der Nest, M.A.; Steenkamp, E.T.; McTaggart, A.R.; Trollip, C.; Godlonton, T.; Sauerman, E.; Roodt, D.; Naidoo, K.; Coetzee, M.P.A.; Wilken, P.M.; et al. Saprophytic and pathogenic fungi in the Ceratocystidaceae differ in their ability to metabolize plant-derived sucrose. BMC Evol. Biol. 2015, 15, 1-20. [CrossRef] [PubMed]

29. Belbahri, L. Genome sequence of Ceratocystis platani, a major pathogen of plane trees. University of Neuchatel. 2015. Unpublished work.

30. Blin, K.; Wolf, T.; Chevrette, M.G.; Lu, X.; Schwalen, C.J.; Kautsar, S.A.; Duran, H.G.S.; Santos, E.L.C.D.L.; Kim, H.U.; Nave, M.; et al. antiSMASH 4.0-Improvements in chemistry prediction and gene cluster boundary identification. Nucleic Acids Res. 2017, 45, W36-W41. [CrossRef]

31. Hedden, P.; Phillips, A.L.; Rojas, M.C.; Carrera, E.; Tudzynski, B. Gibberellin biosynthesis in plants and fungi: A case of convergent evolution? J. Plant. Growth Regul. 2001, 20, 319-331. [CrossRef] [PubMed]

32. Kanehisa, M.; Sato, Y.; Morishima, K. BlastKOALA and GhostKOALA: KEGG tools for functional characterization of genome and metagenome sequences. J. Mol. Biol. 2016, 428, 726-731. [CrossRef]

33. Stanke, M.; Tzvetkova, A.; Morgenstern, B. AUGUSTUS at EGASP: Using EST, protein and genomic alignments for improved gene prediction in the human genome. Genome Biol. 2006, 7, S11. [CrossRef]

34. Solovyev, V.; Kosarev, P.; Seledsov, I.; Vorobyev, D. Automatic annotation of eukaryotic genes, pseudogenes and promoters. Genome Biol. 2006, 7, S10. [CrossRef] [PubMed]

35. Wilson, A.M.; van der Nest, M.A.; Wilken, P.M.; Wingfield, M.J.; Wingfield, B.D. Pheromone expression reveals putative mechanism of unisexuality in a saprobic ascomycete fungus. PLoS ONE 2018, 5, e0192517. [CrossRef] [PubMed]

36. Simpson, M.C.; Wingfield, M.J.; Coetzee, M.P.A.; van der Nest, M.A.; Wingfield, B.D. Mating in Ceratocystis fimbriata. Ph.D. Thesis, University of Pretoria, Pretoria, South Africa, 2018; pp. 122-170.

37. Werck-Reichhart, D.; Feyereisen, R. Cytochromes P450: A success story. Genome Biol. 2000, 1, S3003. [CrossRef] [PubMed]

38. Katoh, K.; Misawa, K.; Kuma, K.I.; Miyata, T. MAFFT: A novel method for rapid multiple sequence alignment based on fast Fourier transform. Nucleic Acids Res. 2002, 30, 3059-3066. [CrossRef] 
39. Kumar, S.; Stecher, G.; Tamura, K. MEGA7: Molecular evolutionary genetics analysis version 7.0 for bigger datasets. Mol. Biol. Evol. 2016, 33, 1870-1874. [CrossRef]

40. Abascal, F.; Zardoya, R.; Posada, D. ProtTest: Selection of best-fit models of protein evolution. Bioinformatics 2005, 21, 2104-2105. [CrossRef] [PubMed]

41. Varga, M.; Bartók, T.; Mesterházy, Á. Determination of ergosterol in Fusarium-infected wheat by liquid chromatographyatmospheric pressure photoionization mass spectrometry. J. Chromatogr. A. 2006, 1103, 278-283. [CrossRef] [PubMed]

42. De Mendiburu, F.; de Mendiburu, M.F. Package 'agricolae'. In R. Package Version; CRAN: Vienna, Austria, $2020 ;$ pp. 1-2.

43. Chen, J.; Zeng, X.; Yang, Y.L.; Xing, Y.M.; Zhang, Q.; Li, J.M.; Ma, K.; Liu, H.W.; Guo, S.X. Genomic and transcriptomic analyses reveal differential regulation of diverse terpenoid and polyketides secondary metabolites in Hericium erinaceus. Sci. Rep. 2017, 7, 10151. [CrossRef]

44. Lepesheva, G.I.; Waterman, M.R. Structural basis for conservation in the CYP51 family. Biochim. Biophys. Acta Proteins Proteom. 2011, 1814, 88-93. [CrossRef]

45. Bhattacharya, S.; Esquivel, B.D.; White, T.C. Overexpression or deletion of ergosterol biosynthesis genes alters doubling time, response to stress agents, and drug susceptibility in Saccharomyces cerevisiae. mBio 2018, 9, e01291-e01318. [CrossRef]

46. Alcazar-Fuoli, L.; Mellado, E.; Garcia-Effron, G.; Lopez, J.F.; Grimalt, J.O.; Cuenca-Estrella, J.M.; Rodriguez-Tudela, J.L. Ergosterol biosynthesis pathway in Aspergillus fumigatus. Steroids 2008, 73, 339-347. [CrossRef] [PubMed]

47. Gachotte, D.; Eckstein, J.; Barbuch, R.; Hughes, T.; Roberts, C.; Bard, M. A novel gene conserved from yeast to humans is involved in sterol biosynthesis. J. Lipid Res. 2001, 42, 150-154. [CrossRef]

48. Gachotte, D.; Barbuch, R.; Gaylor, J.; Nickel, E.; Bard, M. Characterization of the Saccharomyces cerevisiae ERG26 gene encoding the C-3 sterol dehydrogenase (C-4 decarboxylase) involved in sterol biosynthesis. Proc. Natl. Acad. Sci. USA 1998, 95, 13794-13799. [CrossRef]

49. Kruckeber, A.L.; Dickinson, J.R. The Metabolism and Molecular Physiology of Saccharomyces cerevisiae. In Carbon Metabolism, 1st ed.; Dickinson, J.R., Schweizer, M., Eds.; CRC: New York, NY, USA, 2004.

50. Gaber, R.F.; Copple, D.M.; Kennedy, B.K.; Vidal, M.; Bard, M. The yeast gene ERG6 is required for normal membrane function but is not essential for biosynthesis of the cell-cycle-sparking sterol. Mol. Cell. Biol. 1989, 9, 3447-3456. [CrossRef] [PubMed]

51. Munn, A.L.; Heese-Peck, A.; Stevenson, B.J.; Pichler, H.; Riezman, H. Specific sterols required for the internalization step of endocytosis in yeast. Mol. Biol. Cell 1999, 10, 3943-3957. [CrossRef] [PubMed]

52. de Beer, Z.; Duong, T.; Barnes, I.; Wingfield, B.; Wingfield, M. Redefining Ceratocystis and allied genera. Stud. Mycol. 2014, 79, 187-219. [CrossRef] [PubMed]

53. Lerksuthirat, T.; Sangcakul, A.; Lohnoo, T.; Yingyong, W.; Rujirawat, T.; Krajaejun, T. Evolution of the sterol bio-synthetic pathway of Pythium insidiosum and related Oomycetes contributes to antifungal drug resistance. Antimicrob. Agents Chemother. 2017, 61, e02352-e02416. [CrossRef]

54. Veen, M.; Stahl, U.; Lang, C. Combined overexpression of genes of the ergosterol biosynthetic pathway leads to accumulation of sterols in Saccharomyces cerevisiae. FEMS Yeast Res. 2003, 4, 87-95. [CrossRef]

55. Pierson, C.A.; Eckstein, J.; Barbuch, R.; Bard, M. Ergosterol gene expression in wild-type and ergosterol-deficient mutants of Candida albicans. Sabouraudia 2004, 42, 385-389. [CrossRef] [PubMed]

56. Visser, E.A.; Wegrzyn, J.L.; Steenkamp, E.T.; Myburg, A.A.; Naidoo, S. Dual RNA-Seq analysis of the pine-Fusarium circinatum interaction in resistant (Pinus tecunumanii) and susceptible (Pinus patula) hosts. Microorganisms 2019, 7, 315. [CrossRef]

57. Steenwyk, J.L.; Rokas, A. Copy number variation in fungi and its implications for wine yeast genetic diversity and adaptation. Front. Microbiol. 2018, 9, 288. [CrossRef]

58. Osbourn, A. Secondary metabolic gene clusters: Evolutionary toolkits for chemical innovation. Trends Genet. 2010, 26, 449-457. [CrossRef]

59. Keller, N.P.; Turner, G.; Bennett, J.W. Fungal secondary metabolism-From biochemistry to genomics. Nat. Rev. Genet. 2005, 3, 937-947. [CrossRef] [PubMed]

60. Brock, N.L.; Tudzynski, B.; Dickschat, J.S. Biosynthesis of Sesqui- and Diterpenes by the gibberellin producer Fusarium fujikuroi. Chem. Biol. Chem. 2011, 12, 2667-2676. [CrossRef] [PubMed]

61. Young, C.; McMillan, L.; Telfer, E.; Scott, B. Molecular cloning and genetic analysis of an indole-diterpene gene cluster from Penicillium paxilli. Mol. Microbiol. 2001, 39, 754-764. [CrossRef]

62. Zhang, F.L.; Casey, P.J. Protein prenylation: Molecular mechanisms and functional consequences. Annu. Rev. Biochem. 1996, 65, 241-269. [CrossRef]

63. Rozman, D.; Strömstedt, M.; Tsui, L.-C.; Scherer, S.W.; Waterman, M.R. Structure and mapping of the human lanosterol 14 $\alpha$ demethylase gene (cyp51) encoding the cytochrome p450 involved in cholesterol biosynthesis; Comparison of exon/intron organization with other mammalian and fungal cyp genes. Genom. 1996, 38, 371-381. [CrossRef] [PubMed]

64. Mondego, J.M.C.; Carazzolle, M.F.; Costa, G.G.L.; Formighieri, E.F.; Parizzi, L.P.; Rincones, J.; Cotomacci, C.; Carraro, D.M.; Cunha, A.F.; Carrer, H.; et al. A genome survey of Moniliophthora perniciosa gives new insights into Witches' Broom Disease of cacao. BMC Genom. 2008, 9, 548. [CrossRef]

65. Seitz, L.M.; Sauer, D.B.; Burroughs, R.; Mohr, H.E.; Hubbard, J.D. Ergosterol as a measure of fungal growth. Phytopathology 1979, 69, 1202-1203. [CrossRef] 
66. Kok, L.T.; Norris, D.M. Comparative sterol composition of adult female Xyleborus ferrugineus and its mutualistic fungal ectosymbionts. Comp. Biochem. Physiol. Part. B Comp. Biochem. 1973, 44, 499-505. [CrossRef]

67. Axelsson, B.-O.; Saraf, A.; Larsson, L. Determination of ergosterol in organic dust by gas chromatography-mass spectrometry. J. Chromatogr. B Biomed. Sci. Appl. 1995, 666, 77-84. [CrossRef]

68. Lösel, D.M.; Sancholle, M. Fungal lipids. In Lipids of Pathogenic Fungi; CRC Press: Boca Raton, FL, USA, $1996 ;$ pp. $27-62$.

69. Somasekhara, Y.M.; Wali, S.Y.; Bagali, A.N. Ceratocystis fimbriata-A threatening pathogen of pomegranate (Punica granatum Linn.) in northern Karnataka. Res. Crops 2000, 1, 63-66.

70. Scruggs, A.C.; Basaiah, T.; Adams, M.L.; Quesada-Ocampo, L.M. Genetic diversity, fungicide sensitivity, and host resistance to Ceratocystis fimbriata Infecting sweet potato in North Carolina. Plant. Dis. 2017, 101, 994-1001. [CrossRef] [PubMed] 